\title{
ARCTIC DESIGN FOR THE REAL WORLD: BASIC CONCEPTS AND EDUCATIONAL PRACTICE
}

\author{
Svetlana USENYUK-KRAVCHUK ${ }^{1,4}$, Daria AKIMENKO ${ }^{2}$, Nikolai GARIN ${ }^{1}$ and Satu \\ MIETTINEN ${ }^{3}$ \\ ${ }^{1}$ Ural State University of Architecture and Art, Russia \\ ${ }^{2}$ Independent researcher, Italy \\ ${ }^{3}$ University of Lapland, Finland \\ ${ }^{4}$ Tomsk State University, Russian Federation
}

\begin{abstract}
In this article, we outline the potential of design to inform the vision of human existence in severe environmental settings. For that, we propose the Arctic Design (AD) framework as providing new sensitivity to global issues and preparing for the liveable future in the everchanging environment. Through a brief historical overview of the AD origin, we summarize the past and present developments in the field into several concepts, and here present three of them: hybrid culture, context-sensitivity, and continuous adaptation. We illustrate each concept with examples from design educational practice in two relevant universities in Russia and Finland. Through reconsideration of the relationship between humans and technology in the presence of an influential environment, the proposed framework offers researchers and practitioners new ways of understanding and approaching extreme settings, which serve a testing ground for innovative solutions to adaptation problems critical for human survival and sustainable wellbeing.
\end{abstract}

Keywords: Arctic design, hybrid culture, context-sensitivity, continuous adaptation, design education

\section{INTRODUCTION}

The article aims to introduce the Arctic Design, a general theoretical framework for design actions in the extreme environmental conditions, with a focus on human and non-human wellbeing. In the world, where any environment is under the probability of becoming extreme over the next 20-50 years, the very concept of the Arctic goes beyond geographical boundaries. From an imaginary, remote, sparsely populated area full of untapped resources, the Arctic turns into a natural lab and a real testing ground for new life-support solutions and thus provides for a radical reconsideration of the existing technologyaugmented mode of living. We suggest the Arctic Design framework as a new sensitivity towards global issues, as well as a toolkit for harnessing the potential of design and "pointing our design energies in the right direction" $[1$, p. 6] - in this context, to the north.

Although the concept of "Arctic Design" was internationally introduced under this name only in 2012 in the in-house publication by the University of Lapland [2], its origin can be traced back to the early 1980s. At that time, Arctic Design as a holistic vision naturally emerged in two countries - the Soviet Union and Finland, particularly in two universities, respectively: the Ural State University of Architecture and Art (USUAA) and the University of Lapland (ULapland). Despite the similarities of origin, there were some geographical, economic, political, and cultural differences reflected in the formulated understandings of Arctic Design. Also, in both countries (and universities) the definition evolved over the last 30 years undergoing some small refinements as the situated educational and research practice has suggested.

In the case of ULapland, Arctic Design means design grounded in the Arctic, that involves principles and practices of service and industrial design while considering human adaptation to the cold. In terms of theoretical foundation and research, this means, rephrasing Mauri Ylä-Kotola, a critical shift from the emphasis on commerce and technology, with art as the "icing on the cake", towards the alliance of social sciences and environmental thought inspired and facilitated by artistic vision [3, p. 15].

The USUAA's version promotes Arctic design as a professional area that facilitates non-biological human adaptation to and wellbeing in extreme settings through creating tangible or intangible things. In 
this version, the Arctic/North ceases to exist as a mere geographical name but instead becomes a useful and inspirational metaphor pointing to remote, sparsely populated and relatively isolated areas with a lack of urban industry and infrastructure, and - most importantly - with harsh, challenging yet fragile environment.

Nevertheless, both concepts agree upon the Arctic basis as providing fruitful insights into tacit issues of human-nature-technology interaction usually less pronounced / taken for granted in milder climates and more "civilized" environments.

\section{THE BASIC CONCEPTS OF ARCTIC DESIGN}

The exploration into Arctic Design begins from defining what Arctic Design is not: it is not a separate professional sector, like, for example, industrial or graphic design. Moreover, it is not what is usually meant by design specialization, but rather a lens that brings to bear sensitivity to human and non-human wellbeing. This lens is expressed through a set of basic concepts and principles that constitute a general conceptual system applicable, as we argue, to virtually any environmental and social development challenges. The list of concepts presented in the framework of this article includes hybrid culture, context-sensitivity, and continuous adaptation.

The very essence of design as a discipline implies that any concept can (and should) be defined through practical implementation. Thus, the basic concepts of Arctic Design presented below are clarified through briefly described examples - projects conducted respectively at USUAA, and ULapland.

\subsection{Hybrid culture}

The concept of hybrid culture is the overarching and most important one in Arctic Design. However, it is also one of the most ambiguous and thus open to discussion. It comes from cultural studies, particularly from the contemporary postcolonial discourse outlined in seminal works by Homi Bhabha and Mary Louise Pratt [4], [5]. We apply this discourse to the Arctic as a heterogeneous "in-between space" [5] where numerous multicultural non-indigenous newcomers - from exiled immigrants to oil/gas industry workers - currently co-exist with the small-numbered Aboriginal population "often in contexts of highly asymmetrical relations of power" [4, p. 23]. This process of aggressive interaction (collisions, mergers, acquisitions) proceeds with a significant preponderance of the influence of the newcomer population and is accompanied by a thoughtless transfer to the new conditions not only of the objects of the material environment but also of the whole lifestyle from different regionally determined customs, traditions, etc.

The spontaneous formation of hybrid northern materiality entails severe consequences. The first thing that a person perceives in a different culture is not abstract concepts, but concrete (arti)facts. The material world is a direct reflection of cultural norms and values that, in turn, stem from the life tasks arising in front of the bearers of a given culture in a territory. When life tasks and following patterns of behaviour have not yet been established, the inadequate material world becomes the most apparent source of social and environmental conflicts.

However, the relations within multicultural communities can potentially go beyond what is widely meant by hybridization of culture as an inevitable result of colonialism [6, p. 129], and serve as "a precondition for the inventiveness and creativity" [7, p. 3]. The extreme, unforgiving, and noncompromised environment of the Arctic provides a fruitful testing ground for new forms of people's coexistence, namely "fluid communities," where the metaphor of fluidity means a lighter, more adaptable and mobile way of dwelling in the world [8, p. 18]. In the Arctic case, we already have a working example of such multilateral adaptation, that is the culture of the indigenous population, particularly reindeer nomads. Their unique experience of comfortable living in extreme conditions has been coded in their material world, too. In contrast to the spontaneous, multicultural import, the things of indigenous nomads - undergone a profound natural selection and deeply rooted in everyday life have eventually become "necessary and sufficient" not only in practical terms but also in aesthetic characteristics.

In this vein, the task for designers is to learn from this exemplar: "to analyse and adopt existing design principles from the Arctic and to make these available to the rest of the world while respecting the intellectual property of indigenous peoples" [9, p. 57]. Hence, the process of "decolonization by design" [10], which implies competent design interpretation of indigenous knowledge, objects, technologies decoding and adapting them to the specifics of the new coming population (physiology, mentality, etc.) - is a professional challenge for designers and an opportunity to bring closer the appearance of the 
"exemplary things" in our multicultural reality. Important to note that Arctic design approach at its best is aimed not at indigenous inhabitants but non-indigenous temporary visitors. The goal of so-called arctic designers is to provide decision-makers with ethically and aesthetically appropriate, visually convincing concepts that would support non-indigenous individuals on short/mid/long-term "Arctic missions," and, at the same time, not disturb (and - at best - empower) local dwellers.

The revisited concept of hybridity/hybridization thus provides fresh insights into timely topics of adaptation, participation, community and cultural identity [11], [12] and, on a practical level, informs designers in their work toward creating "social innovation that transforms the existent by taking steps toward sustainability" [8, p. 22]. The material outputs of this strategy would not belong to any of the mixed cultures separately, but together give rise to the "synergetic third" - the object/material shell of the hybrid culture.

\subsubsection{Examples of hybrid culture}

The examples of the systemic projects on cultural design are still limited to the domain of short-term visits, namely Arctic tourism development. In 2012, a group of seven students of USUAA developed an experimental tourist complex "Novaya Zemlya," a hypothetical model of comfortable human existence in the Far North, with geographical reference to the same-named archipelago in the Arctic Ocean. The outcome was the system of socio-technological interaction with the environment, implemented through the following components: a detailed scenario of events and actions/activities of tourists during the trip; sets of personal equipment for the identified variety of tourist activities; personal equipment for emergency rescue; mobile dwelling units; a chain of personal and communal transport vehicles that facilitates various kinds of tourist mobility; means of physical and psychological relaxation for extreme/adventure tourist trips; and an overall visual design concept of the tourist facilities. More information and images: [49].

Given the ULapland's cross-disciplinary approach to both students' training and implementation of projects, the local issues are often tackled by the faculty of Art and Design in collaboration with other Faculties and scientific departments (e.g. Social Sciences, Education, Arctic Centre, or the Multidimensional Tourism Institute) and external actors (e.g. artists' associations, local municipalities). These types of projects often approach societal issues in a co-creative manner starting from workshops with the groups, and stakeholders, communities in question to collect user data and devise a course of action together.

Among the examples of such community-oriented projects there is a service design project Good Life in Villages conducted together with local municipalities in order to address the problems of depopulation, as well as decrease of funding and infrastructure in the villages of Finnish Lapland, and as a result decrease of life quality of the ageing population. As a result of co-design sessions, the community of Autti village devised a course of potential grassroots developments they can undertake, further interviews also showed the growth of community spirit and closeness. More details and images: [14].

\subsection{Context-sensitivity}

The term "context-sensitive" clarifies the practical relationship of designers with the Indigenous cultural heritage within the framework of hybrid culture: not ignoring, but learning from, and not blindly preserving traditions, but keeping them alive and available for the present and future [15]. This term emphasizes the focus on protecting, appreciating and enriching not just historical cultural resources, but also those generated and accumulated by today's communities and environment.

With the aim of transforming traditions, that is, as Nardi points out, "finding new ways to apply the wisdom of organizing human activity around community, simplicity, equality, and care /.../" [1, p. 14], we turn to works of Italian philosopher Gianni Vattimo arguing that in a postmodern situation the architect's job (and that of the designer) is "to listen, to accept, and to negotiate rather than to create something new" [16, p. 46]. Thus, in order to facilitate fusion of cultures - and eventually to create a hybrid culture - design professionals have to examine various values and intra-cultural distinctions thoroughly, as well as to clearly define what, why and how to ethically borrow from the natives.

\subsubsection{Examples of context-sensitivity}

Again, within the Arctic tourism domain, the USUAA student Alexandra Nikolaeva developed "The Crow Day Celebration" - a context-sensitive adaptation of the homonymous traditional festivity of the 
Nenets people. This festivity signifies the end of a quasi-endless winter (a Winter Year) and the arrival of long-awaited spring (a Summer Year). She carefully examined the entire set of rituals related to the traditional Crow Day, and divided them into three groups: (1) entirely sacred that are performed by a particular part of the community, for example, young girls or elderly women and forbidden for participation or even observation by other members; (2) partly sacred, when spectators are allowed, but participation is restricted; and (3) open/public, when everyone can join and enjoy the celebration. At the next stage, she proposed the cultural basis for design interpretation: The North-originated Crow Day was tangibly and spiritually associated with widely recognized (multiculturally acknowledged) celebration of New Year. The design outcomes included essential attributes for a new/old ritual, such as a stylized New Year Tree, special food, a thematic carnival with masks and costumes, and the culminating ceremony of making a wish.

Working in sensitive indigenous contexts has been one of the priorities for ULapland, too. The geographical closeness to different Sámi groups of Finnish, Swedish and Norwegian Lapland, as well as those of the Kola peninsula in Russia, allows for hands-on exchanges. One of the more long-term projects that took place over 2010-2014 was DAVVI [17]. It involved non-indigenous students and teachers of ULapland and Indigenous students and teachers at Sámi University College in Kautokeino (Norway) and Sámi Education Institute in Inari (Finland). The Sámi counterparts provided in-depth traditional and academic knowledge on the socio-cultural and historical realities and the traditional crafts which shape the whole approach towards creating material environment in the scarce conditions of the Arctic (the approach called "doudji"). The curriculum was designed so that the methodologies from "westernised" Social Sciences and Interior and Product Design would interlace and compare themselves with those from traditional craftsmanship. The outcomes included a dozen of students' projects (mostly traditional Sàmi objects created in consultancy with the craftsmen and adapted ergonomically to serve a wider range of contemporary purposes). Besides, the project ensured further inclusion into the faculty curriculum the bilateral workshops and consultancy sessions, as well as the approach of "duodji" as one of the concepts taught to young designers.

\subsection{Continuous adaptation}

While the concept of hybrid culture positions the Arctic Design approach at the societal level, the term continuous adaptation illuminates the scope of activities at the level of an individual. The concept of adaptation as "a spatial concentration of effort" [18, p. 118] comes from biology and medical studies, where it describes the process of change by which an organism or species becomes better suited to its environment.

Within the Anthropocene paradigm and particularly the discourse of global change, adaptation usually refers to a process, action or outcome in a system (household, community, group, sector, region, country) in order for the system to better cope with, manage or adjust to changing conditions, stress, hazard, risk or opportunity [19, p. 282].

In our case, the vast expanses of the Arctic remain sparsely populated, despite the long history of their development. The severe environmental conditions constitute a difficult-to-surmount barrier to comprehensive - physiological and psychological - adaptation for people from lower latitudes. As mentioned above, organic getting used to the Arctic is impossible without a profound restructuring of both physiological processes inside the human body and the "cultural core," namely values, traditions, skills, technologies used, as well as of the surrounding material world. The very idea of "cultural adaptation" coined by the anthropologist and cultural ecologist Julian Steward, describes the necessary adjustments of regional societies to the natural environment through subsistence activities [19, p. 283], [20]. Through the lens of Arctic Design, these activities represent a necessary and sufficient nonbiological response to severe environmental conditions and thus constitute the subject matter of professional interest.

We employ the adaptation concept to identify and characterize the process of continuous adjustment, repair, repurpose and redesign of material objects (and related user practices) that enable and support sustainable interaction between a non-native human and the everchanging severe environment.

\subsubsection{Examples of continuous adaptation}

"An Ideal Northern ATV" is an iterative project on developing locally appropriate all-terrain vehicles for remote, roadless areas with severe climate conditions conducted at USUAA in 2018-2020 (ongoing). The goal is to come up with a design-driven foresight of micro-mobility in the geographical periphery. 
During the first part, students explored the phenomenon of "vernacular design," also known as - since Soviet times - the movement of DIY-enthusiasts of garage-making and tinkering and selected several regions of Russia based on local DIY-activities. The design proposals are built upon existing vehicles invented by local makers and users from those settlements. The next round will include discussions of design proposals with authors of original machines and then iterative ideation and development. More information and images [21].

Service Innovation Corner (SINCO), a Service Design prototyping lab, has been in use at ULapland for nearly 9 years now. It is a space defined by large screen walls and a system of projectors that allow to create an immersive representation of virtually any situation. Additional accessories and materials are used as aids in the process of this immersive planning. Since its early days, the objectives of the lab included being able to prototype design contexts and situations in a "safe" adaptable environment, as well as "to study and analyse existing service journeys, visualize ideas and develop them quickly and evaluate concepts collaboratively". The obvious pluses of such space available for young designers in the Arctic conditions is the ability to design for outdoor and "offsite" situations that would not otherwise be easily reachable. Inviting users, focus groups and stakeholders to co-prototype together in the lab creates an even more inclusive space. The easily transformable environment allows for ongoing adaptation and adjustment of design prototypes and further services and products. More details and images: http://sinco.fi/.

\section{CONCLUSIONS}

From an academic perspective, this article represents a rare attempt to document and "scientifically legalize" the original research ideas sprang up far (north) from the strongholds of global modernity. Arctic Design, while not a universal approach, can offer valuable insights to enhance the design theory and practice. Its orienting contribution to the complex design landscape appears twofold. First, it seems particularly useful for highlighting the tacit issues of the relationship between human and technology in the presence of an influential environment when environmental variables are hard to specify and impossible to control directly. Second, it draws attention to alternative ways (practices) of approaching and getting used to such an environment.

As for the latter, with its original geographical reference, Arctic Design contributes to topical discussions on sustainability. Indeed, in the Arctic context, sustainability as an essential systemic feature appears in the form of both dramatic environmental challenge and a desired developmental outcome. The latter applies to, as Michael Hardt asserts, "Arctic indigenous peoples' dignified existence." He goes even further proposing Indigenous people to be our teachers on the way towards sustainability by design [9, p. 59]. Overall, the Arctic Design's contribution to sustainability discussions sets on the socio-technical system innovation level (According to categorization by [22]). With the alternative solutions to fulfilling individual and social needs based on necessity and sufficiency in the severest possible context, it aims to support "transitions to new socio-technical systems" [22, pp. 3, 19].

One of the critical limitations of the presented framework that indicates the direction for further improvement is that the number of Indigenous members of the design research community is still small. As asserted along the lines, the presented framework aims to serve the needs of emerging "hybrid" community, and therefore urgently calls for the equitable input from both sides, namely newcomers' and Indigenous. This is, indeed, a social obligation for design education to raise a new kind of "hybrid" design professionals - people trained to understand the complexity of environmental, social and cultural contexts, to use the means and methods of facilitating multilateral cooperation, in addition to understanding economics and politics [23, p. 354]. Within the educational settings of USUAA and ULapland, there are already attempts to engage Indigenous students through bachelor's and master's degree programs as well as specialized short-term courses under the framework of the University of the Arctic / Arctic Sustainable Art and Design Network. These attempts already signify the "broken ice" on the way of making actual Indigenous voices freely expressed and be heard.

\section{ACKNOWLEDGEMENTS}

Funding for this work comes from the Russian Science Foundation, the project "Arctic Design: Methods of Technical Aesthetics for Development and Appropriation of the Russian Far North" (grant No. 1778-20047). 


\section{REFERENCES}

[1] Nardi, B. "Design in the Age of Climate Change," She Ji: The Journal of Design, Economics, and Innovation, vol. 5, no. 1, pp. 5-14, 2019, doi: 10.1016/j.sheji.2019.01.001.

[2] Tahkokallio, P. Ed., Arctic Design - Opening the Discussion. University of Lapland, 2012.

[3] Ylä-Kotola, M. "Arctic Design. Is there such a thing?" in Arctic Design - Opening the Discussion, University of Lapland, 2012, pp. 12-15.

[4] Pratt, M. L., "Arts of the contact zone," Profession, no. 1, pp. 33-40, Jan. 1991.

[5] Bhabha, H.K. "Culture's in-between," in Questions of cultural identity, S. Hall and P. Du Gay, Eds. London; Thousand Oaks, Calif: Sage, 1996, pp. 53-60.

[6] Ashcroft, B. Griffiths, G. and Tiffin, H., The empire writes back: theory and practice in postcolonial literatures. London; New York: Routledge, 1989.

[7] MacCannell, D., Empty meeting grounds: the tourist papers. London; New York: Routledge, 1992.

[8] Manzini, E., Politics of the everyday. London: Bloomsbury Visual Arts, 2019.

[9] Hardt, M., "The story of the frozen ice or the art of sustainable design in the Arctic," in Arctic Design - Opening the Discussion, P. Tahkokallio, Ed. University of Lapland, 2012, pp. 54-59.

[10] Schultz, T., et al., "What Is at Stake with Decolonizing Design? A Roundtable," Design and Culture, vol. 10, no. 1, pp. 81-101, Jan. 2018, doi: 10.1080/17547075.2018.1434368.

[11] Irani, L., Vertesi, J., Dourish, P., Philip, K. and Grinter, R.E., "Postcolonial computing: a lens on design and development," in Proceedings of the 28th international conference on Human factors in computing systems, New York, NY, 2010, pp. 1311-1320.

[12] Muller, M. and Druin, A., "Participatory Design: The Third Space in Human- Computer Interaction," in Human-Computer Interaction Handbook, Boca Raton, FI: CRC Press, 2012, pp. $1125-1154$.

[13] Usenyuk, S. and Gostyaeva, M. "Arctic Tourism: the Design Approach with Reference to the Russian North," in The Interconnected Arctic-UArctic Congress 2016, Springer, 2017, pp. 231241.

[14] Akimenko, D. and Kuure, E. "Narrative Identities in Participatory Art and Design Cases," in Nordes 2017: Design+Power, Oslo, Norway, 2017, vol. 7, pp. 1-9, Accessed: Oct. 19, 2019. [Online]. Available: http://www.nordes.org/nordes2017/assets/full_papers/nordes17a-sub1031cam-i26_AKIMENKO_v2.pdf.

[15] Nugraha, A. Transforming tradition: a method for maintaining tradition in a craft and design context. Helsinki: Aalto Univ., School of Arts, Design and Architecture, 2012.

[16] Vattimo, G. "Postmodernity and New Monumentality," Res: Anthropology and aesthetics, vol. 28, pp. 39-46, Sep. 1995, doi: 10.1086/RESv28n1ms20166928.

[17] Tompuri, H. and Kalla, A.M., "DAVVI Multidisciplinary Academic Training Project 20102014," University of Lapland, Rovaniemi, 2014. [Online]. Available: https://www.ulapland.fi/loader.aspx?id=735fa4a2-d7cf-4547-b511-00effd696a68.

[18] Selye, H. The stress of life. New York; Toronto; London: McGraw-Hill Book Company, 1976.

[19] Smit, B. and Wandel, J. "Adaptation, adaptive capacity and vulnerability," Global Environmental Change, vol. 16, no. 3, pp. 282-292, Aug. 2006, doi: 10.1016/j.gloenvcha.2006.03.008.

[20] Butzer, K.W. "Cultural ecology," in Geography in America, G. L. Gaile and C. J. Willmott, Eds. Columbus, Ohio: Merrill Publishing Co., 1989, pp. 192-208.

[21] Usenyuk-Kravchuk, S., Garin, N., Klyusov, N., Dedevich, N. and Pokataeva M., "Light, Local, Repairable: A Designerly Exploration into an Ideal All-Terrain Vehicle," The International Journal of Designed Objects, vol. 13, no. 3-4, 2019, doi: 10.18848/2325-1379/CGP/v13i02/114.

[22] Ceschin, F. and Gaziulusoy, I. "Evolution of design for sustainability: From product design to design for system innovations and transitions," Design Studies, vol. 47, pp. 118-163, Nov. 2016, doi: 10.1016/j.destud.2016.09.002.

[23] Lou,Y. "Designing Interactions to Counter Threats to Human Survival," She Ji: The Journal of Design, Economics, and Innovation, vol. 4, no. 4, pp. 342-354, 2018, doi: 10.1016/j.sheji.2018.10.001. 